\title{
FATIGUE CRACK GROWTH AND PROBABILITY ASSESSMENT FOR TRANSVERSE TIG WELDED ALUMINUM ALLOY 6013-T4
}

\author{
GunAWAN D. HARYADi \\ Diponegoro University, Department of Mechanical Engineering, Semarang, Indonesia \\ Rando Tungga Dewa \\ Pukyong National University, Department of Mechanical Design Engineering, Busan, Korea \\ e-mail:rando.td@gmail.com
}

I.M.W. EKAPUTRA

Sanata Dharma University, Department of Mechanical Engineering, Yogyakarta, Indonesia

\begin{abstract}
The aim of this study is to investigate the fatigue crack growth behavior with post weld heat treatments (T4) on transverse tungsten inert gas-welded Aluminum alloy 6013. All fatigue tests have been carried out using center cracked tension specimens at ambient temperature under a stress ratio of $R=0.3$. The results revealed that various time of aging in $\mathrm{T} 4$ affects its mechanical properties, also the fatigue crack growth behavior as well. It has been observed that in the heat treated samples the crack growth rate is lower than that in the as-welded sample, but higher than the rate in the base metal. To be more specific, samples with 18 hours aging exhibit the highest tensile strength and fatigue resistance compared to the other heat treated samples. The probability assessment has also been used to determine the fatigue crack growth rate and a good linearity has been found.
\end{abstract}

Keywords: fatigue crack growth, Aluminum alloy 6013-T4, post welding heat treatment, TIG welding

\section{Introduction}

The aircraft and automotive industries have been long using Aluminum alloys for the prime material construction. This material is normally used in the aerospace industry (for fuselage skins and other applications) and automotive industry (for body panels and bumpers) due to its excellent properties such as preferential strength, corrosion resistance, weld ability and low cost. Various structural components in machines, pressure vessels, transport vehicles, earthmoving equipment and spacecraft are made of welded joints. The butt welds are the most common ones in the fabrication and construction of many structures. The wide applications of butt welds in various structures including offshore and nuclear ones give a large scope for researches to analyze the behavior under different types of loading conditions. This concept was introduced after the works of Yakubovski and Valteris (1989). However, as it is well known, welded joints can exhibit poor fatigue properties. Thus, detail design guidelines are necessary to prevent fatigue failures in welded Aluminum alloy structures. Apart from the basic design of new structures, there is also an increase of interest in methods for assessing the remaining life of existing structures. The previous author's work also revealed the fatigue crack growth behavior of the studied material using longitudinal direction of tungsten inert gas (TIG) welding (Haryadi and Kim, 2011). Prompted by difficulties experienced in reaching a consensus on fatigue performance of welded Aluminum alloys, an animated discussion has been undertaken over the past 10 years (Maddox, 2003). 
To produce a high quality weldment component, TIG welding is preferred rather than the other arc welding processes due to the temperature distribution on the welded plate, which may induce distortion. Also the TIG welding process is one of the most well established processes which has capabilities to weld all metals of industrial use. Therefore, many efforts have been done to investigate the fatigue behavior on TIG welded Aluminum alloy joints. The weldment components have lower impact energy and fracture tenacity compared to its parent material. It is well known that the welded structures are also less superior to the parent material as the welding process (thermal interaction) results in microstructure heterogeneity, which brings differences to mechanical properties (Manti et al., 2008). Failure analysis of the weldment indicates that fatigue damage have to be considered to account for most of the disruptive failures. The main problem is that there is an abrupt change in section due to the excess weld reinforcement, undercut, slag inclusion and lack of penetration, and nearly $70 \%$ of fatigue cracking occurs in the welded joint (Pakusiewicz et al., 2006). It is also well known that the heat treatment process after welding, i.e. solution treatment and aging, can possibly overcome the degradation of mechanical properties.

To determine the fatigue tendency of the weld structure, the test matrix of tests is more complex as welded joints present microstructure variations over small distances, not to mention complex distributions of residual stresses. The fatigue and fracture tests are performed in accordance with standards and codes devised by the American Society for Testing and Materials (ASTM) E647 based on the concepts of $a-N$ and $(d a / d N)-\Delta K$ for fatigue design curves.

This work deals with the dependence of constant-amplitude fatigue crack growth rates on the center cracked tension (CCT) specimens of a material for a variety of heat-treatable thin-sheet Aluminum alloys. The TIG welded 6013 Aluminum alloy transverse joint is of particular interest. A better understanding of the relatively high variability of these rates and the role of material parameters based on the analysis of experimental data are explored and discussed for assessing the remaining lives of existing structures.

\section{Experimental section}

The material studied is Aluminum alloy 6013 with sheet thickness of $2.5 \mathrm{~mm}$. The chemical composition of Aluminum alloy 6013-T4 and its filler wire Al 5356 can be found in Table 1 (Rooy, 2000). The welding process by using the TIG method on specimens has been performed by Al 5356 filler with $3.2 \mathrm{~mm}$ diameter, and the welding was done in the transverse direction. The welding conditions and process parameters can be found in (Haryadi and Kim, 2011). Tensile test specimens were made with dimensions according to the standard test ASTM B-557, and crack propagation tests specimens according to the standard test ASTM E-647 proposed by American Society of Mechanical Engineers (ASME) (ASTM E 647-08, 2008). The specimens were grouped into three kinds of fracture conditions, i.e. cracks without heat treatment, cracks in the welding simulation, and cracks in the welding simulation continued with various T82 artificial aging. The surfaces of the specimens were polished to prevent the formed notches. The geometry and dimensions of specimens are specified in Fig. 1.

Table 1. Chemical composition of Al 6013-T4 and filler wire Al 5356 [wt\%]

\begin{tabular}{|c|c|c|c|c|c|c|c|c|c|}
\hline References & $\mathrm{Si}$ & $\mathrm{Fe}$ & $\mathrm{Cu}$ & $\mathrm{Mn}$ & $\mathrm{Mg}$ & $\mathrm{Cr}$ & $\mathrm{Zn}$ & $\mathrm{Ti}$ & $\mathrm{Al}$ \\
\hline \hline $\mathrm{Al} 6013$ & 0.66 & 0.09 & 0.80 & 0.39 & 1.04 & 0.07 & 0.06 & 0.02 & $\mathrm{Bal}$ \\
\hline $\mathrm{Al} 5356$ & 0.25 & 0.40 & 0.10 & 0.10 & 5.55 & 0.20 & 0.10 & 0.20 & $\mathrm{Bal}$ \\
\hline
\end{tabular}

The heat treatment (T4) on the specimen is hereafter referred to as the specimen experiencing the process of solution treatment (the specimen is heated until it reaches the temperature 


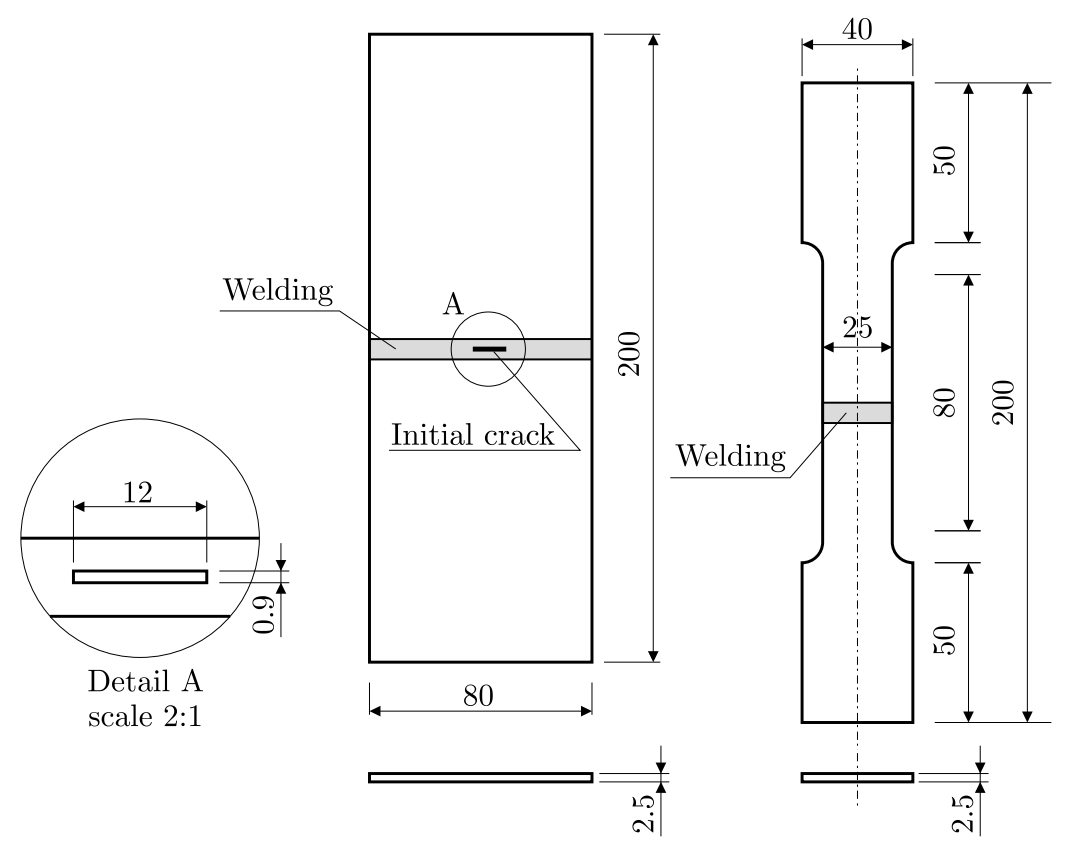

Fig. 1. Specimen configuration for tensile and fatigue crack propagation tests (all units in millimeters)

of $420^{\circ} \mathrm{C}$ ), followed by a process of strain hardening of $2 \%$, and the final process is the artificial aging in temperature of $175^{\circ} \mathrm{C}$ and the aging time of 6 hours, 18 hours, and 24 hours, respectively. Microhardness measurements have been conducted through fusion boundaries using a Vickers microhardness tester. Vickers hardness measurement was carried out by using a diamond indenter on a metallographically polished section of the welded joint along the central line at a loading of $0.2 \mathrm{~kg}$ and loaded time of $5 \mathrm{~s}$. The indentations were set at an interval of $1 \mathrm{~mm}$ along the weld center, transverse to the direction of the base metal. The schematic illustration of hardness testing distribution is shown in Fig. 2. The microstructures of all material types are shown in Fig. 3. The as-welded material has a larger grain size compared to the other heat treated samples. Coarser grained by 24 hours aging time samples relatively contained a lower amount of grain boundary areas than the finer grained microstructure.

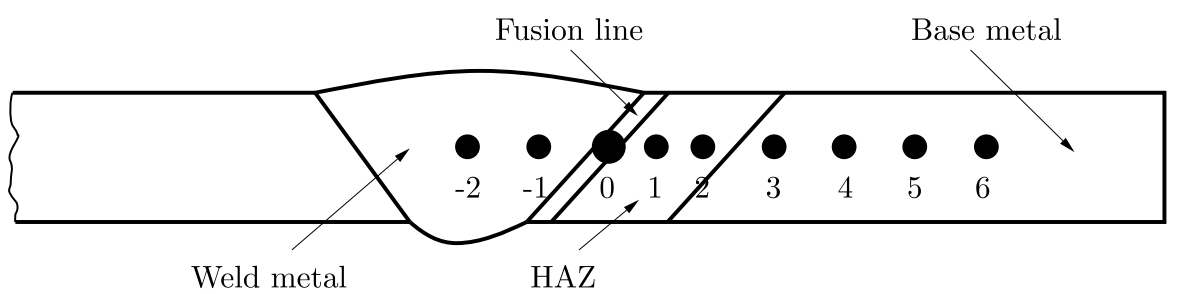

Fig. 2. Welding profiles and a schematic illustration of the hardness testing distribution

Initial cracks for the fatigue crack propagation CCT samples were made using EDM (Electric Discharge Machine) with $12 \mathrm{~mm}$ length and $0.9 \mathrm{~mm}$ width. The fatigue crack growth tests were carried out using side grooves to ensure the crack propagation occur along a single plane. Five different stress levels (345 MPa, 225 MPa, $138 \mathrm{MPa}, 202 \mathrm{MPa}$, and $170 \mathrm{MPa}$ ) were applied under a stress ratio of $R=0.3$ with a constant frequency of $5-11 \mathrm{~Hz}$. A travelling microscope was used to monitor the crack growth with an accuracy of $0.01 \mathrm{~mm}$. In this work, the applied stress cycle was in the pull mode as the compressive mode usually near the fatigue crack. The data points measured with an accuracy of $0.01 \mathrm{~mm}$ were fitted with a smooth curve as in the form of crack length against the number of cycles. 

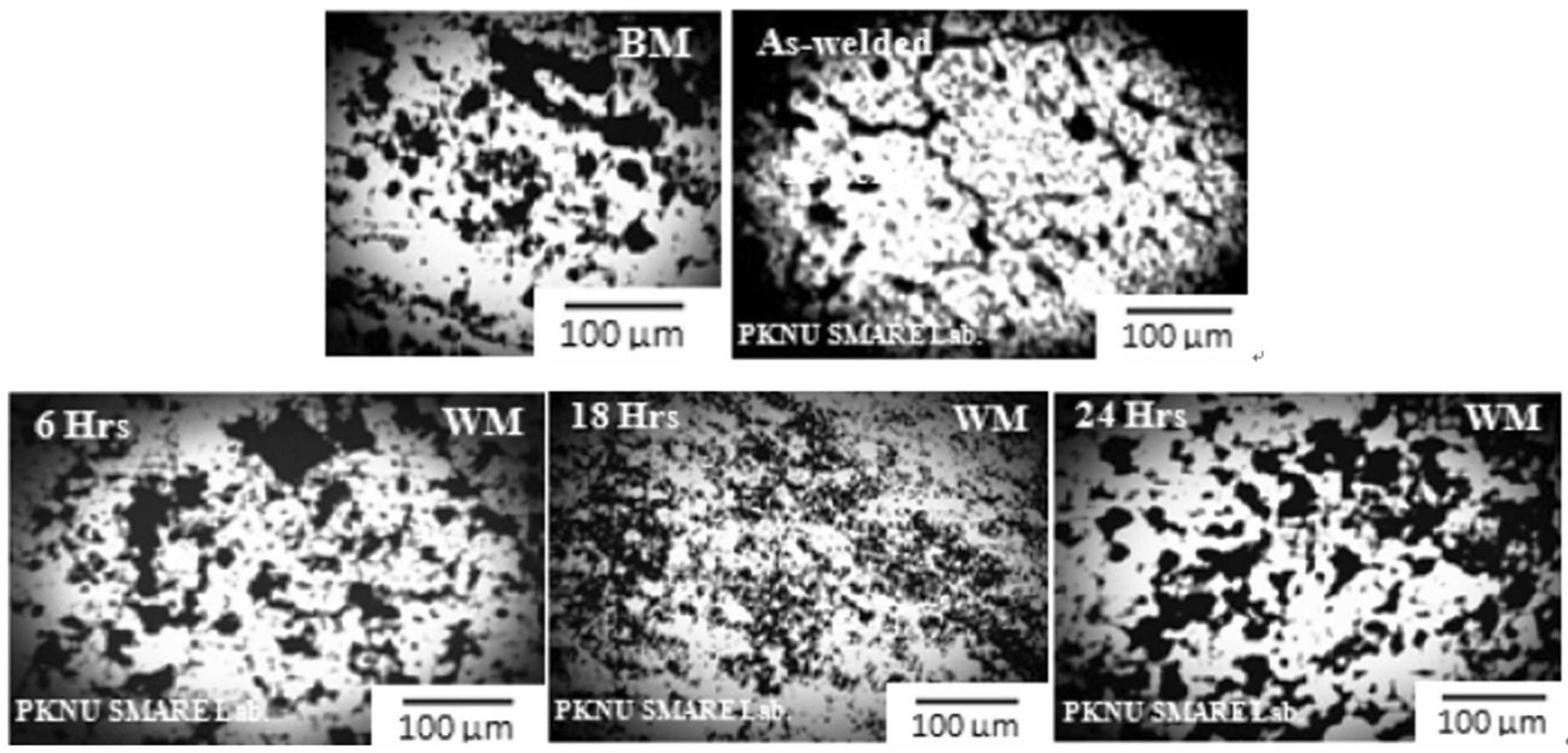

Fig. 3. Microstructures of as-welded and 6013-T4 samples (BM: base metal and WM: Weld metal)

\section{Results and discussions}

\subsection{Tensile properties of 6013-T4}

The tensile test results were performed on the base metal, welding without T4, and welding with T4 aging time variations. The results of the tensile tests are mean values of minimum three tests. All tensile test failures occurred in the heat affected zone (HAZ) due to coarser grains as the cast structure of the base material. As such, the reduced section and notched specimens were made to characterize the failure from the welded metal. The yield strength results based on $0.2 \%$ offset in the load-elongation diagram and the peak maximum (ultimate tensile) strength are reported in Fig. 4. The unwelded base metal indicates yield strength and tensile strength values of $243 \mathrm{MPa}$ and $346 \mathrm{MPa}$, respectively. These results are comparable to other literature data (Heinz and Skrotzki, 2002) for 6013-T4 base metal having the yield and ultimate strength approximately 220 and $320 \mathrm{MPa}$, respectively. Thus, the transverse as-welded sample shows the yield strength and tensile strength values of $141 \mathrm{MPa}$ and $227 \mathrm{MPa}$, respectively. From this result, we can point out that there is a $52 \%$ reduction in strength values due to the TIG welding process in the transverse direction. The as-welded material possesses higher strength or embrittlement, therefore, very slight lateral displacement will result in shearing off the structure. In the case of the as-welded samples, the transverse TIG welded samples with 6 hours aging exhibit the lowest yield strength and tensile strength of $82 \mathrm{MPa}$ and $160 \mathrm{MPa}$, respectively. This suggests that there is a $42 \%$ reduction in strength due to T4with a 6 hours aging process compared to the transverse as-welded samples. The heat treated specimens with 18 hours aging indicate the highest yield strength and tensile strength of $107 \mathrm{MPa}$ and $202 \mathrm{MPa}$, respectively. Though these values are lower than those for the base metal and as-welded samples, the strength values are comparatively higher than those of the other samples with T4 process. The 24 -hour aged samples show the yield strength and tensile strength of $102 \mathrm{MPa}$ and $194 \mathrm{MPa}$, respectively, which is $20 \%$ higher than the heat treated samples by 6 hours aging. To conclude all those cases, no significant influence of the welding direction compared to the previous study (Haryadi and Kim, 2011) has been reported.

The percentage of elongation in the cross sectional area of the base material and transverse as-welded samples can be seen in Fig. 5. The elongation in the cross sectional area of the base metal and the transverse as-welded samples are $19.42 \%$ and $5.83 \%$, respectively. According to 


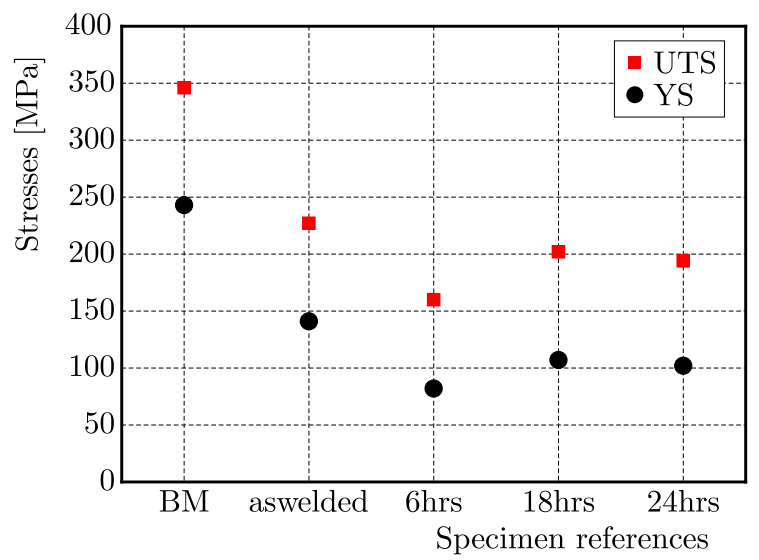

Fig. 4. Results of tensile tests on the strength of various transverse TIG welded 6013-T4 samples

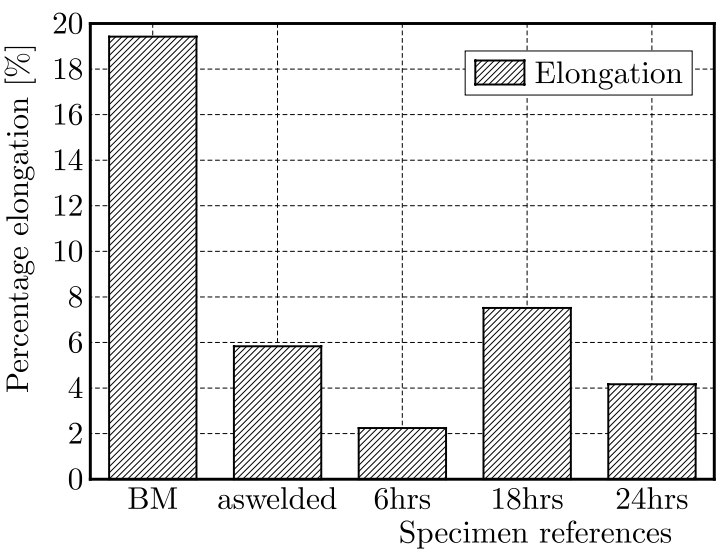

Fig. 5. Reduction in area in terms of elongation [\%] of transverse TIG welded 6013-T4

the literature (Heinz and Skrotzki, 2002), the elongation for 6013-T4 base metal is comparable, approximating $20 \%$. The increase of strength of the as-welded samples has been expected as the microstructure hardens due to the solidification process during welding. The transverse TIG welded samples with T4 of 6,18 , and 24 hours exhibit $2.24 \%, 7.51 \%$ and $4.16 \%$ of elongation in the cross sectional area, respectively. This suggests that there is a $60 \%$ reduction in ductility due to T4 with 6 hours aging with respect to the transverse as-welded samples. Again, the heat aged specimens for 18 hours indicate the highest elongation of $7.51 \%$. The heat treatment process, especially the 18-hour aging, can improve ductility properties significantly.

\subsection{Microhardness analysis}

The exact extension of the HAZ and welded region are not easily measurable, thus, each indentation of microhardness profiles was drawn based on three average points for the best condition obtained. Hence the mechanical characteristics of heat-treatable Aluminum alloy are largely determined by characteristics of precipitates (i.e. size, volume fraction, composition, distribution, etc.). Precipitates and second phase particles act as obstacles to dislocation movement, which in turn increases hardness and strength but also limits ductility of the material. Precipitation hardening of Al-Mg-Si alloys has also been reported to occur due to increased energy requirement to break Mg-Si bond rather than coherency strains (Haryadi and Kim, 2011). The TIG welding process has proven to affect the original state and distribution of those precipitates. The base metal in its initial number 4-6 condition has the average hardness of about $91 \mathrm{HV}$ approximately, which starts to slightly increase in the HAZ to a minimum of $100 \mathrm{HV}$. The 
hardness is greatly reduced in the welded region irrespective of the welding processes (Fig. 6). This is one of the reasons for location of the failure invariably at the welded region. The closer to the center of the weld, the higher the temperature is reached, which may lead to coarsening of the grain structure. The coarsening becomes an important aspect in the welded region due to the thermally activated phase in this particular zone. Thus, the softening phase caused by precipitation coarsening will also soften the material. The time aging by T4 possesses limits the strength due to high temperatures resulting in finer grains (Effertz et al., 2016), and reprecipitation accompanied by aging. The ductility of this Aluminum alloy can be enhanced by a proper heat treatment process. The T4 sample aged by 6 hours indicates the lowest hardness profiles about $50 \mathrm{HV}$ at the weld center. The T4 sample with 18 hours aging shows the highest hardness of about $71 \mathrm{HV}$ at the welded region. It is important to emphasize that the transverse as-welded sample has the highest hardness of about $77 \mathrm{HV}$ at the welded region.

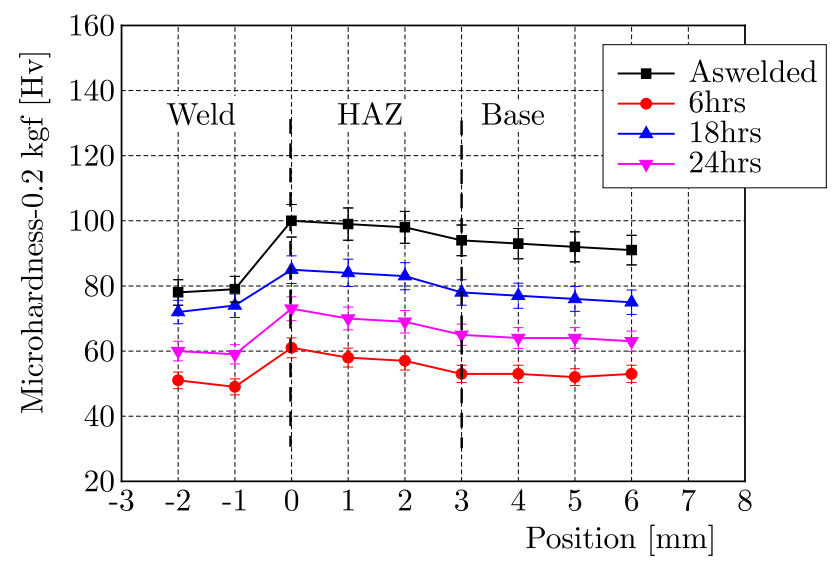

Fig. 6. Vickers microhardness profile distribution across the welded zone

With the combination of tensile properties and microhardness profiles, it is also possible to determine mechanical properties of the transverse welded butt joint with 18 hours aging, which are the most superior compared to other aging processes. The aging by 18 hours is more appropriate for more brittle materials (high strength). After this time of aging, the detriment of the mechanical properties can be observed due to the over aging process.

\section{3. $\quad$ Fatigue crack growth properties}

It is well known that the growth of the fatigue crack of many materials can be divided into three regimes as shown in Fig. 7. Region I is the fatigue threshold region where $\Delta K$ is too low to propagate the crack. Region II involves the rate of crack growth changes roughly linearly with a change in the stress intensity factor (SIF). Lastly, region III with a small increase in the SIF, produces a relatively large increase in the crack growth rate.

Considering the power law region, the experimental results for the crack length $a$ are plotted in $d a / d N$ versus $\Delta K$, with $N$ and $\Delta K$ being the number of cycles and SIF, respectively, according to the following Paris equation (Paris and Erdogan, 1963)

$$
\frac{d a}{d N}=C(\Delta K)^{m}
$$

where the correlation between the exponent $m$ and the coefficient $C$ in the Paris equation determines the material constants. The crack growth exponent $m$, which is derived from the relationship existing between the crack growth rate $d a / d N$ and the SIF range, is an important parameter to evaluate the fatigue crack growth behavior of materials since it decides about the fatigue crack propagation life of the materials (Dieter, 1988). 


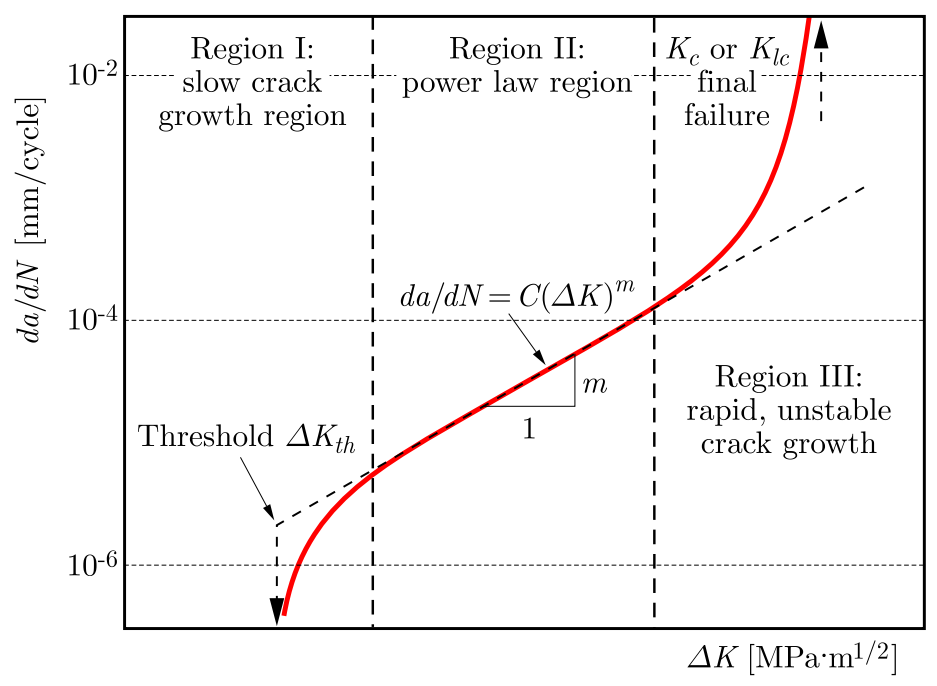

Fig. 7. Fatigue crack propagation curve

The loading variables $R, \Delta K$, and $K_{\max }$ are related in accordance with the range of the SIF with the following relationship (Malarvizhi et al., 2008), where $\sigma$ is a uniform tensile stress perpendicular to the crack plane and $Y$ depends on the geometry of samples

$$
\Delta K=Y \sqrt{\pi a} \quad N=\int_{a_{i}}^{a_{f}} \frac{1}{C(\Delta K)^{m}} d a
$$

where $a_{i}$ and $a_{f}$ are initial crack length and crack length at the fracture point, respectively. The crack growth rate, $d a / d N$ for the propagation stage is calculated for the steady state growth regime at different intervals of crack length increment, against the associated number of cycles to propagation. The SIF values are calculated for different values of the growing fatigue crack length $2 a$ using the following expression for the middle tension specimen refering to the ASTM Standard. The measured variation in the crack length $2 a$ and the corresponding number of cycles $N$ endured under the action of particular applied stress range are plotted in Fig. 8.

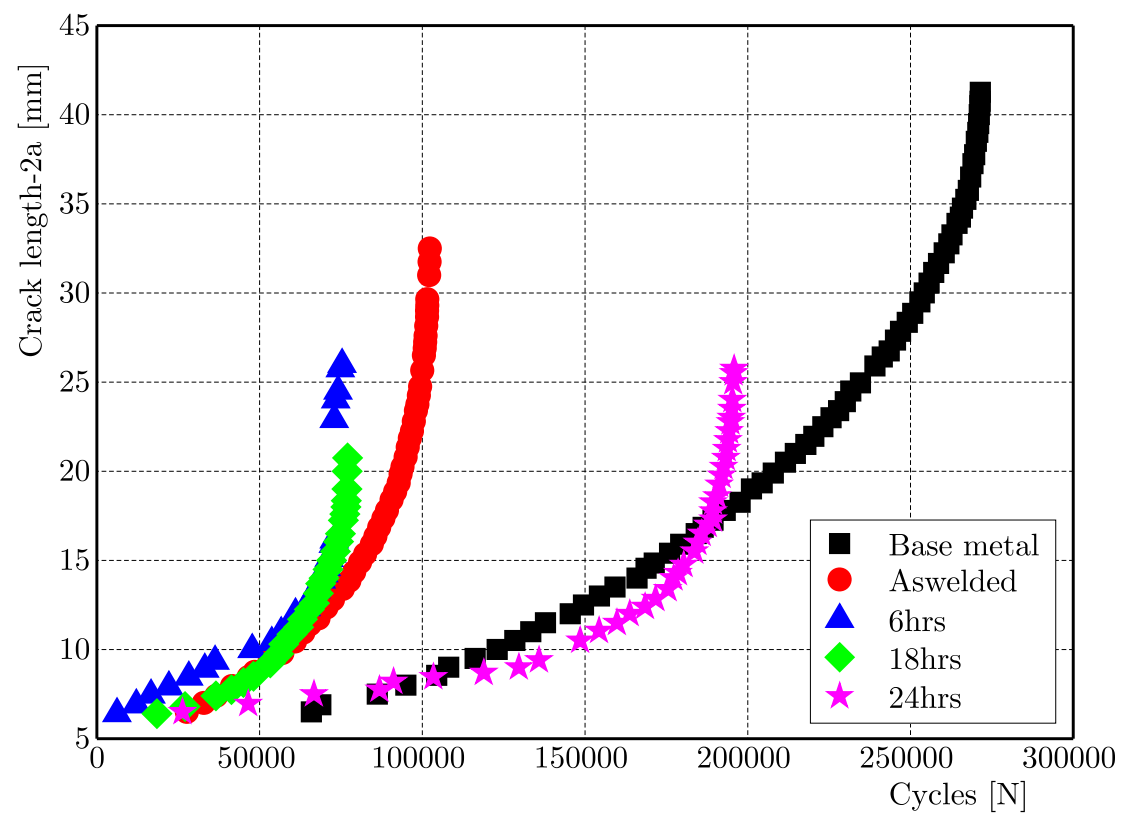

Fig. 8. Fatigue crack propagation curve of transverse TIG welded 6013-T4 
The relationship between the SIF and $\Delta K$ range and the corresponding crack growth rate $d a / d N$ in terms of the best fit lines is shown in Figs. 9a and $9 \mathrm{~b}$ for all samples. The data points plotted in the graph mostly correspond to the second stage of the Paris sigmoidal relationship (10E-6 to $10 \mathrm{E}-3 \mathrm{~mm} / \mathrm{cycle}$ ). The exponent $m$, which is the slope of the line on log-log plot and the intercept $C$ of the line, are determined and presented in Table 2.
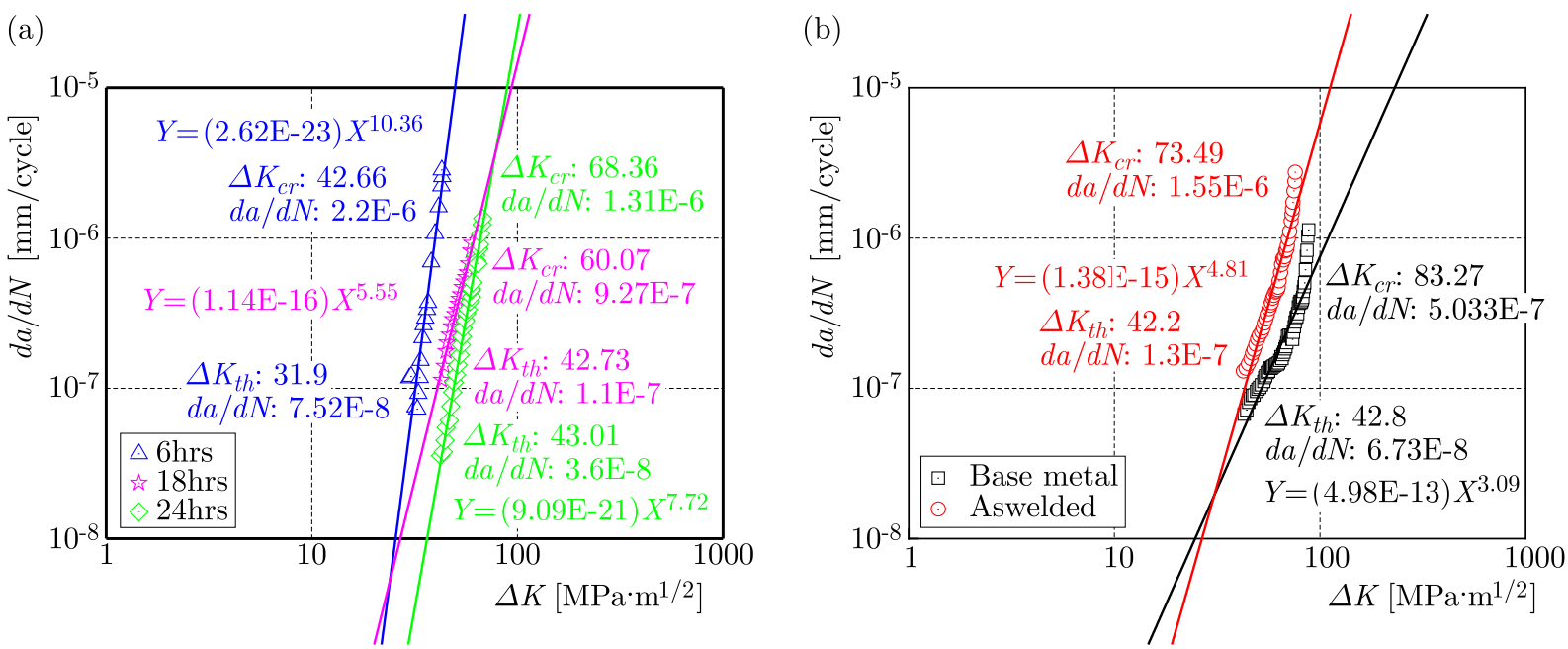

Fig. 9. (a) Fatigue crack growth for Al 6013-T4 (base metal) and the transverse as-welded sample.

(b) Measured fatigue crack growth for the transverse TIG welded 6013-T4

Table 2. Fatigue crack growth parameters of transverse TIG welded samples

\begin{tabular}{|l|c|c|}
\hline \multicolumn{1}{|c|}{ References } & $\begin{array}{c}\text { Crack growth } \\
\text { exponent } m\end{array}$ & $\begin{array}{c}\text { Coefficient } \\
C\end{array}$ \\
\hline \hline Al 6013 base metal & 3.09 & $4.98 \mathrm{E} 10-13$ \\
\hline Transverse TIG welded & 4.81 & $1.38 \mathrm{E} 10-15$ \\
\hline After 6 hours aging & 10.36 & $2.62 \mathrm{E} 10-23$ \\
\hline After 18 hours aging & 5.55 & $1.14 \mathrm{E} 10-16$ \\
\hline After 24 hours aging & 6.74 & $9.09 \mathrm{E} 10-21$ \\
\hline
\end{tabular}

It can be seen from those figures that at higher crack growth rates, the measured fatigue crack growth rate for the base metal is $5.03 \mathrm{E}-7 \mathrm{~mm} /$ cycle $\left(\Delta K_{c r}=84.2 \mathrm{MPa} \sqrt{\mathrm{m}}\right)$, and the measured fatigue crack growth rate for transverse as-welded samples is $1.55 \mathrm{E}-6 \mathrm{~mm} /$ cycle $\left(\Delta K_{c r}=73.49 \mathrm{MPa} \sqrt{\mathrm{m}}\right)$. On the other hand, in Fig. $9 \mathrm{~b}$ for all $\mathrm{T} 4$ samples, at higher crack growth rates for 6 hours aging, 18 hours aging and 24 hours aging samples exhibit 2.2E-6 mm/cycle $\left(\Delta K_{c r}=42.66 \mathrm{MPa} \sqrt{\mathrm{m}}\right), 9.27 \mathrm{E}-7 \mathrm{~mm} /$ cycle $\left(\Delta K_{c r}=60.07 \mathrm{MPa} \sqrt{\mathrm{m}}\right)$, and $1.31 \mathrm{E}-6 \mathrm{~mm} /$ cycle $\left(\Delta K_{c r}=68.36 \mathrm{MPa} \sqrt{\mathrm{m}}\right)$, respectively. The unstable crack growth phase occurred and, hence, the corresponding $\Delta K$ value is taken as the critical SIF range $\Delta K_{c r}$. Furthermore, the crack growth at a lower rate is found to be dormant, and the corresponding $\Delta K$ value is taken as the threshold SIF $\left(\Delta K_{t h}\right)$. At a lower crack growth rate, the measured fatigue crack growth rate for the base metal is $6.73 \mathrm{E}-8 \mathrm{~mm} /$ cycle $\left(\Delta K_{t h}=42.8 \mathrm{MPa} \sqrt{\mathrm{m}}\right)$ and the measured fatigue crack growth rate for transverse as-welded samples is $1.3 \mathrm{E}-7 \mathrm{~mm} / \operatorname{cycle}\left(\Delta K_{t h}=42.2 \mathrm{MPa} \sqrt{\mathrm{m}}\right)$. Thus, at a lower crack growth rate for all T4 samples with 6 hours aging, 18 hours aging and 24 hours aging results in $7.52 \mathrm{E}-8 \mathrm{~mm} /$ cycle $\left(\Delta K_{t h}=31.9 \mathrm{MPa} \sqrt{\mathrm{m}}\right), 1.1 \mathrm{E} 10-7 \mathrm{~mm} / \mathrm{cycle}$ $\left(\Delta K_{t h}=42.73 \mathrm{MPa} \sqrt{\mathrm{m}}\right)$, and $3.6 \mathrm{E}-8 \mathrm{~mm} / \operatorname{cycle}\left(\Delta K_{t h}=43.01 \mathrm{MPa} \sqrt{\mathrm{m}}\right)$, respectively.

The fatigue crack growth exponent of the Al 6013-T4 Aluminum alloy base metal is lower than that of the transverse TIG samples. On the three heat treated samples with various aging, 
the 18 hours aging samples exhibit a very low fatigue crack growth exponent compared to the other heat treated samples. Although, the fatigue crack growth exponent of 18 hours aging samples is approximately $44 \%$ higher than in the base metal. It is understood that the 18 hours aging samples exhibit superior fatigue crack growth resistance compared to the other heat treated samples. If this exponent has a larger value, then the slope of the curve is higher what explains lower resistance of the material to the growing fatigue crack and reduction the lifespan (Ambriz et al., 2010; Sivaraj et al., 2014). The reasons for better fatigue crack growth resistance of the 18 hours aging samples is due to superior of mechanical properties. The crack tip plasticity is also the reason of the higher crack growth rate, since the deformation is controlled by the yield strength of the material and mainly concentrated in the welded metal zone. The extension of the plastic zone size (PZS) is limited within the welded metal. This relationship indicates that the local fatigue crack growth rate decreases when the SIF is increased, and can be estimated by the following equation (Sohn et al., 2014)

$$
P Z S_{(\text {cycle })}=0.033\left(\frac{\Delta K}{\sigma_{y s}}\right)^{2}
$$

Eripret and Hornet (1994) reported that as soon as the plastic zone reaches the fusion line, plasticity keeps on developing along the interface between the parent material and the weld metal. The triaxial state of stress is high in the weld metal and the relaxation of this stress is poor. The crack driving force needed for this crack extension is small. Hence, the fracture toughness of the lower strength weld metal is not high. On the other hand, if the strength of the weld metal is more or less equal to the base metal, the plastic zone can easily extend into the parent material.

An extensive research by Zhang et al. (2016) did not deal with probabilistic viewpoints that define the probability of fracture. In this circumstance, a quantifiable method based on a statistical and probabilistic approach is proposed for assessing fatigue crack growth rate data. As mentioned above, the fatigue crack growth data followed the lognormal distribution well if using the standard deviation $\sigma$ and mean value $\mu$ obtained from the lognormal distribution. The probability density functions (PDF) for this distribution is

$$
P(N, \text { loc }, \text { scale })=\frac{1}{\sigma \sqrt{2 \pi}} \exp \left[-\frac{1}{2}\left(\frac{\ln N-\mu}{\sigma}\right)^{2}\right]
$$

As an example of application, Fig. 10 shows the probability distribution on the fatigue crack growth data for 18 hours aging samples. The fatigue crack growth life was estimated from the initial crack length of $8.5 \mathrm{~mm}$ to $17.6 \mathrm{~mm}$. To the author's best knowledge, the lognormal distribution provides a good agreement for the statistical distribution of fatigue crack growth life. The confidence intervals of $90 \%$ and $10 \%$ will be the upper and lower limits of conventional prediction for the fastest and lower fatigue crack growth rate according to the concept in the literature (Kim et al., 2011).

To probabilistically predict the fatigue crack growth rate, the probabilistic distributions of $d a / d N$ have been determined for various materials. Figure 11 shows a typical result for the probability distribution of the $d a / d N$ for various materials. The relationships between the probability and fatigue crack growth life data revealed a linear relationship in the lognormal plot. Although, there are some variability linear equations between material types. The most scattered and widely distributed values are revealed for the 6 hours aging samples. This also proves that the TIG welded microstructure and the heat treatment time process could greatly affect the fatigue crack growth life. Using these fatigue crack growth rate data, it is possible to probabilistically predict the fatigue crack growth rate lines for this class of materials at the operational temperature when the fatigue crack growth data is absent. 


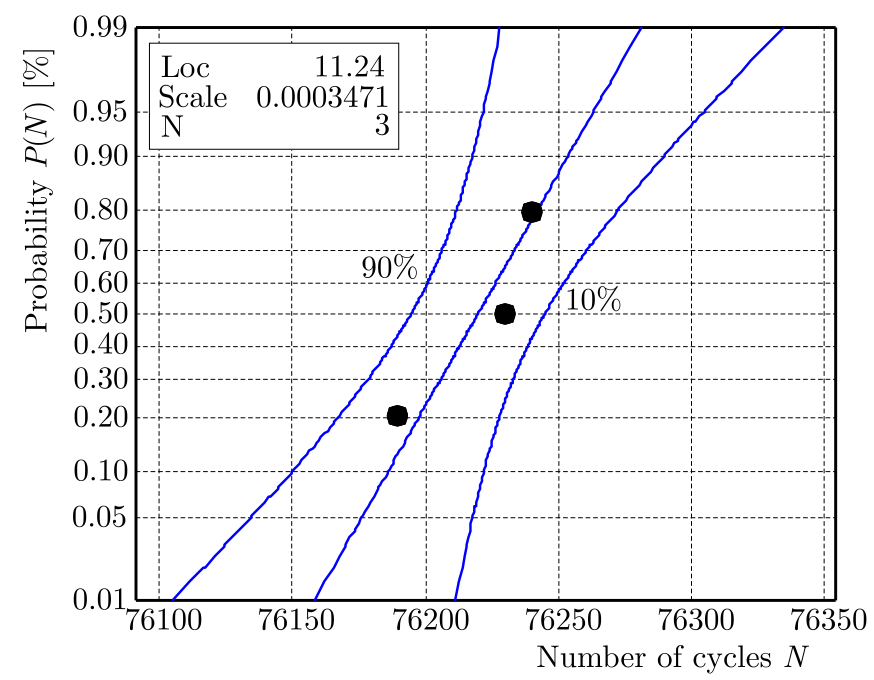

Fig. 10. Probability distribution of the fatigue crack growth life $N$ for 18 hours aging samples

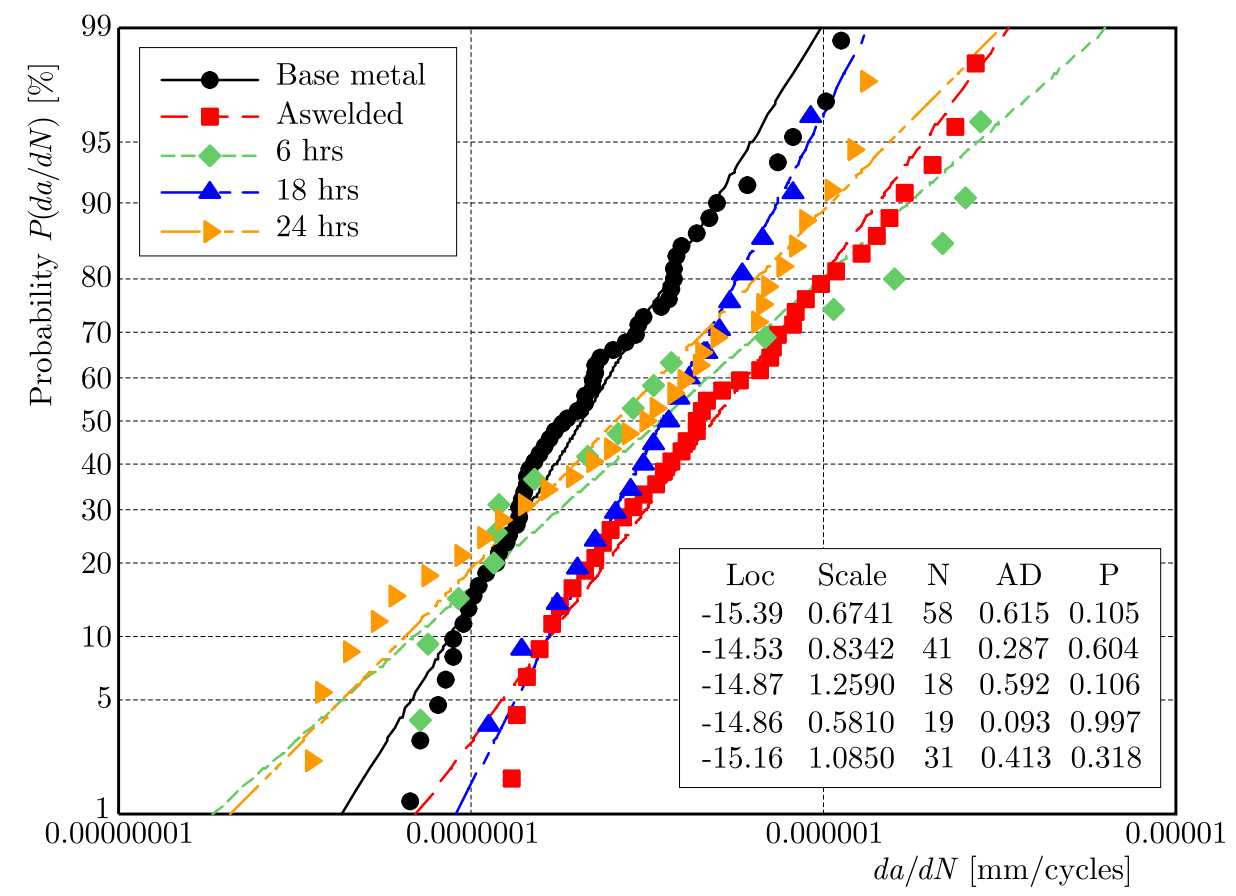

Fig. 11. Log-normal distribution of the fatigue crack growth rate for all tested samples at average $N$ values

\section{Concluding remarks}

This paper presents results of tensile, hardness profile, fatigue crack growth behavior and probabilistic analysis of transverse TIG welded Al 6013-T4. However, some aspects deserve attention and are discussed in this Section. The following conclusions can be drawn:

- A $52 \%$ reduction in strength values due to the TIG welding process in the transverse direction with respect to the base material has been observed. Thus, the heat treatment process also can reduce the strength by about $20 \%$ in average despite the percentage of elongation of the respected T4 materials has been increased with respect to the as-welded material. 
- The fatigue crack growth resistance and fatigue life of Al 6013-T4 are generally reduced by the TIG welding process. Of the three types of T4 samples, the 18 hours aging samples exhibit a higher fatigue crack growth resistance compared to other heat treated samples.

- The effect of 18 hours aging showed a crack growth exponent $m$ of 5.55 which is the lowest value compared to the other heat treated samples. With a high $\Delta K$ (SIF), it causes a dramatic increase in the crack growth resistance compared to the other heat treated samples.

- The relationships between probability and fatigue crack growth life data exhibit linearity of the lognormal plot. The variability of the fatigue crack growth life is influenced by the TIG welded microstructures and T4 aging time.

\section{Acknowledgements}

This research was supported through research grant of Diponegoro University and Pukyong National University (2017). Special gratitude is granted to prof. Seon Jin-Kim, PhD (Pukyong National University) for technical discussions and supports.

\section{References}

1. Ambriz R.R., Mesmacque G., Ruiz A., Amrouche A., López V.H., Benseddiq N., 2010, Fatigue crack growth under a constant amplitude loading of Al-6061-T6 welds obtained by modified indirect electric arc technique, Science and Technology of Welding and Joining, 15, 6, 514-521

2. ASTM E 647-08, 2008, Standard Test Method for Measurement of Fatigue Crack Growth Rates, American Society for Testing Materials (ASTM), New York, U.S.A.

3. Dieter G.E., 1988, Mechanical Metallurgy, 4th ed., Tata McGraw Hill, New York, U.S.A.

4. Effertz P.S., Infante V., Quintino L., Suhuddin U., Hanke S., Dos Santos J.F., 2016, Fatigue life assessment of friction spot welded 7050-T76 aluminium alloy using Weibull distribution, International Journal of Fatigue, 87, 381-390

5. Eripret C., Hornet P., 1994, Prediction of overmatching effects on the fracture of stainless steel cracked welds, [In:] Miss-Matching of Welds, ESIS 17, K.H. Schwalbe, M. Koçak (Edit.), London, $685-708$

6. Haryadi G.D., Kim S.J., 2011, Influences of post weld heat treatment on fatigue crack growth behavior of TIG welding of 6013-T4 aluminum alloy joint. Part 1. Fatigue crack growth across the weld metal, Journal of Mechanical Science and Technology, 25, 9, 2161-2170

7. Heinz B., Skrotzki B., 2002, Characterization of a friction-stir-welded aluminum alloy 6013 , Metallurgical and Materials Transactions B, 33B, 489-498

8. Kim W.G., Park J.Y., Hong S.D., Kim S.J., 2011, Probabilistic assessment of creep crack growth rate for Gr. 91 steel, Nuclear Engineering and Design, 241, 3580-3586

9. MAddox S.J., 2003, Review of fatigue assessment procedures for welded aluminium structures, International Journal of Fatigue, 1359-1378

10. Malarvizhi S., Raghukandan K., Viswanathan N., 2008, Investigations on the influence of post weld heat treatment on fatigue crack growth behaviour of electron beam welded AA2219 alloy, International Journal of Fatigue, 30, 1543-1555

11. Manti R., Dwivedi D.K., Argawal A., 2008, Pulse TIG welding of two Al-Mg-Si alloys, ASM International, 17, 6, 667-673

12. Paris P.C., Erdogan F.A., 1963, Critical analysis of crack propagation laws, Journal of Basic Engineering, Transactions ASME (Series D), 85, 528-534 
13. Pukasiewicz A.G.M., Henke S.L., Casas W.J.P., 2006, Effect of post-weld heat treatment on fatigue crack propagation in welded joints in CA6NM martensite stainless steel, Welding International, 20, 12, 947-952

14. Rooy E.L., 2000, Introduction to aluminum and aluminum alloys, ASM Handbook, 2

15. Sivaraj P., Kanagarajan D., Balasubramanian V., 2014, Fatigue crack growth behaviour of friction stir welded AA7075-T651 aluminium alloy joints, Transactions of Nonferrous Metals Society of China, 24, 2459-2467

16. Sohn H.J., Haryadi G.D., Kim S.J., 2014, Statistical aspects of fatigue crack growth life of base metal, weld metal and heat affected zone in FSWed 7075-T651 aluminum alloy, Journal of Mechanical Science and Technology, 28, 10, 3957-3962

17. Yakubovski V.V., VAlteris I.I., 1989, Geometrical parameters of butt and fillet welds and their influence on the welded joint fatigue life, International Institute of Welding, Document XIII, 132689

18. Zhang X., Wang S., Yan X., Yue D., Sun R., Zhou X., 2016, Probabilistic analysis for the functional and structural fatigue of NiTi wires, Materials and Design, 102, 213-224

Manuscript received March 2, 2017; accepted for print August 31, 2017 